\title{
Anatomical risk factors, surgical treatment, and clinical outcomes of left-sided pulmonary vein obstruction in single-ventricle patients
}

\author{
Yasuhiro Kotani, MD, $\mathrm{PhD},{ }^{\mathrm{a}}$ Jiaquan Zhu, MD, PhD, ${ }^{\mathrm{a}}$ Lars Grosse-Wortmann, $\mathrm{MD},{ }^{\mathrm{b}}$ \\ Osami Honjo, MD, PhD, ${ }^{\mathrm{a}}$ John G. Coles, MD, ${ }^{\mathrm{a}}$ Glen S. Van Arsdell, MD, ${ }^{\mathrm{a}}$ and \\ Christopher A. Caldarone, $\mathrm{MD}^{\mathrm{a}}$
}

\begin{abstract}
Background: Patients with single-ventricle physiology frequently develop leftsided pulmonary vein obstruction (PVO), in which the pulmonary veins traverse the descending thoracic aorta. We hypothesized that a combination of cardiomegaly and an anteriorly positioned descending aorta is associated with PVO.

Methods: Among 494 consecutive single-ventricle patients, 15 were diagnosed with PVO by cardiac magnetic resonance, defined as anatomically localized narrowing of the pulmonary vein diameter. Using axial slices at the level of the left lower pulmonary vein, normalized dimensions were obtained to characterize the anatomic relationships of intrathoracic structures. Measurements were compared between patients with PVO and "control" patients (single-ventricle patients with normal pulmonary veins, $\mathrm{n}=12$ ).
\end{abstract}

Results: Patients with cardiac magnetic resonance-diagnosed PVO had larger cardiac size and more antero-laterally located descending aorta when compared with controls (normalized dimensions: cardiac/thoracic area ratio: 0.43 vs 0.38 , $P=.035$, distance from vertebra to descending aorta normalized by the horizontal dimension of thoracic cavity: 0.09 vs $0.08, P=.049)$. Seven $(47 \%)$ patients underwent PV sutureless repair, and 3 (of 7) failed to achieve Fontan. Patients who failed to achieve Fontan had a larger normalized cardiac size than those who achieved Fontan (cardiac/thoracic area ratio: 0.49 vs $0.39, P=.001$ ).

Conclusions: The combination of relative cardiomegaly within the context of the thoracic cavity at the level of the pulmonary veins and antero-lateral displacement of the aorta is associated with left-sided PVO and subsequent failure to achieve Fontan completion. Further characterization of these unique geometric relationships may help inform both surveillance strategies and decision making in the timing of interventions, and guide the intraoperative objectives at the time of PVO repair. (J Thorac Cardiovasc Surg 2015;149:1332-8)

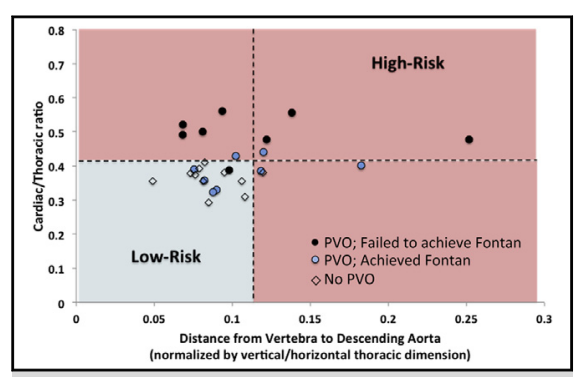

Combination of cardiomegaly and antero-latellary located descending aorta is a risk for left PVO.

\section{Central Message}

Characterization of both anatomic and physiologic feature of left PVO helps decision making in the timing and type of repair.

\section{Perspective}

In comparison with biventricular repair, the clinical significance of PVO is magnified in patients with single-ventricle physiology because PVO may prevent progression to second stage and Fontan procedures. This study showed that combination of cardiomegaly and anterolaterally displaced descending aorta was associated with left PVO and subsequent failure to achieve Fontan completion; hence, further characterization of this unique condition is important.

See Editorial page 1245.
Previous studies have noted that left-sided pulmonary vein obstruction (PVO) commonly occurs in close proximity to the descending thoracic aorta. ${ }^{1-3}$ In comparison with biventricular repair, the clinical significance of PVO is magnified in patients with single-ventricle physiology

From the Divisions of Cardiovascular Surgery ${ }^{\mathrm{a}}$ and Cardiology, ${ }^{\mathrm{b}}$ The Labatt Family Heart Centre, The Hospital for Sick Children, University of Toronto, Toronto, Canada.

Read at The 2013 American Heart Association Scientific Sessions, Dallas, Texas, November 17-20, 2013.

Received for publication May 27, 2014; revisions received Oct 25, 2014; accepted for publication Nov 29, 2014; available ahead of print Jan 31, 2015.

Address for reprints: Christopher A. Caldarone, MD, Division of Cardiovascular Surgery, Hospital for Sick Children, 555 University Ave, Toronto, Ontario, Canada M5G 1X8 (E-mail: christopher.caldarone@sickkids.ca).

0022-5223/\$36.00

Copyright (c) 2015 by The American Association for Thoracic Surgery

http://dx.doi.org/10.1016/j.jtcvs.2014.11.089 because PVO may prevent progression to second stage and Fontan procedures. Indeed, atrioventricular valve regurgitation (AVVR), which is commonly associated with single-ventricle volume loading, and PVO remain important risk factors for Fontan failure. ${ }^{4,5} \mathrm{We}$ hypothesized that a combination of cardiomegaly and an anteriorly displaced descending aorta predisposes patients to left-sided PVO in the region where the pulmonary veins traverse the descending aorta (Figure 1). To test this hypothesis, we developed geometric models of intrathoracic anatomy using cardiac magnetic resonance (CMR) imaging obtained in patients with and without evidence of PVO. Furthermore, we correlated these anatomic models with progression to Fontan completion. Finally, we evaluated clinical outcomes in terms of Fontan candidacy of this unique pathology. 

Abbreviations and Acronyms
AVVR $=$ atrioventricular valve regurgitation
$\mathrm{CMR}=$ cardiac magnetic resonance
$\mathrm{IQR}=$ interquartile range
$\mathrm{PVO}=$ pulmonary vein obstruction

\section{METHODS}

A total of 494 single-ventricle patients who underwent staged Fontan palliation at The Hospital for Sick Children in Toronto between January 2000 and June 2012 were reviewed. Patients with total anomalous pulmonary venous connection were excluded. Twenty-four $(4.9 \%)$ patients were diagnosed with left-sided PVO. Among the 24 single-ventricle patients with PVO, 15 had left-sided PVO, defined as anatomically localized narrowing of the PV diameter by CMR, and were included as the study group (Table 1); the remaining 9 patients were diagnosed on the basis of echocardiograms (ie, no CMR) and were excluded because the planned anatomic comparisons require CMR studies.

A control group was selected among single-ventricle patients who did not have a diagnosis of left-sided PVO and did have CMR studies available for comparison. Matching criteria included age, ventricular morphology, type of initial palliation, and stage of palliation. Twelve patients were selected for the control group based on matching criteria and the availability of CMR for comparison. Approval for the study was granted by The Hospital for Sick Children Research Ethics Board, which waived any requirement for patient consent.

\section{Diagnostic Studies}

The CMR protocol was performed on a 1.5-Tesla magnet (Avanto, Siemens Medical Solutions, Erlangen, Germany) and consisted of phase contrast flow velocity measurements of all great arteries and veins, as described elsewhere. ${ }^{6}$ Using an axial slice at the level of the left lower pulmonary vein, normalized dimensions were obtained to characterize the anatomic relationships of intrathoracic structures. The slice was selected to maximize the diameter of the most stenotic portion of the pulmonary veins in PVO patients and to go through the midpoint of the left pulmonary veins in the control patients (Figure 2). If the assessments of the 2 investigators differed, the image was reviewed until consensus was reached. Raw measurements were normalized using vertical and horizontal thoracic dimensions. The pulmonary to systemic flow ratio (Qp/Qs) was calculated by using CMR, as follows:

Right pulmonary veins flow $\left(\frac{l}{\min }\right)+$ Left pulmonary veins flow $\left(\frac{l}{\min }\right)$

Descending aortic flow $\left(\frac{l}{\min }\right)+$ Superior vena cava flow $\left(\frac{l}{\min }\right)$

The cardiothoracic ratio at the time of PVO was assessed by chest radiograph. Severity of AVVR was obtained from the echocardiographic assessment close to the time that left-sided PVO was diagnosed (in the study group) or that CMR was performed (in the control group). More than mild AVVR was considered to be significant AVVR. Patients who did not achieve Fontan completion or who required heart transplantation were categorized as being in the "failure group."

\section{Surgical Technique}

Seven $(47 \%)$ patients underwent pulmonary vein sutureless repair. A detailed surgical description has been provided elsewhere. ${ }^{7}$ In brief, moderate hypothermic cardiopulmonary bypass was used. The posterior pericardium and the anterior wall of the left pulmonary veins were opened and unroofed. The anterior wall of the individual pulmonary veins were cut back and unroofed if necessary. The anastomosis between the atrium and the posterior pericardium was performed with a continuous suture technique, using 6-0 or 7-0 polypropylene sutures (Prolene, Ethicon, Inc, Somerville, NJ).

\section{Statistical Analysis}

Continuous data are presented as median (interquartile range [IQR]). Discrete data are presented as frequency (percentage). The level of statistical significance was set at $P \leq .05$. Differences between the groups were analyzed with the Mann-Whitney $U$ test. Event frequencies were compared with $\chi^{2}$ analysis.

\section{RESULTS}

Among patients with left-sided PVO, the left lower pulmonary vein was the most frequent site of obstruction in 13 of 15 patients $(87 \%)$ (Table 1$)$. PVO was diagnosed between stage I and II in 5 patients, between stage II and III in 9 patients, and after Fontan completion in 1 patient. Seven $(47 \%)$ patients had corroborative echocardiographic evidence of physiologic PVO (flow acceleration with mean gradients of $>3 \mathrm{~mm} \mathrm{Hg}$ ). Eight patients did not have any evidence of PVO on echocardiography, defined as a mean gradient of $>3 \mathrm{~mm} \mathrm{Hg}$ across the pulmonary vein. Seven patients (47\%) with PVO had significant AVVR, and 2 patients $(17 \%)$ in the control group had significant $\operatorname{AVVR}(P=.10)$.

\section{Anatomic and Physiologic Relationship of Intrathoracic Structures}

The CMR-derived intrathoracic dimensions are shown in Table 2. The normalized distance from vertebra to aorta in patients with left-sided PVO was greater than that in control patients (0.09, IQR [0.08-0.10] vs 0.08, IQR [0.07-0.09], $P=.049)$. Patients with left-sided PVO had a larger cardiac cross-sectional area normalized to total thoracic crosssectional area than control patients (cardiac/thoracic: 0.43, IQR [0.39-0.49] vs 0.38, IQR [0.36-0.38], $P=.035)$. This difference was accentuated in the comparison of the portion of the cardiac area in the left portion of the thorax (left cardiac/left thoracic: 0.60, IQR [0.52-0.64] vs 0.52 , IQR [0.47-0.54], $P=.014$ ). The comparison of physiologic data showed a non-statistically significant trend toward less left-pulmonary vein flow in patients with left-sided PVO compared with controls (1.02 vs 1.57 $1 / \mathrm{min} / \mathrm{m}^{2}, P=.061$ ) (Table 3). In contrast, patients with left-sided PVO had larger right-pulmonary vein flows (2.25 vs $1.47 \mathrm{l} / \mathrm{min} / \mathrm{m}^{2}, P=.025$ ); therefore, the left-toright PV flow ratio was lower in PVO patients compared with controls $\left(0.52\right.$ vs $\left.1.05 \mathrm{l} / \mathrm{min} / \mathrm{m}^{2}, P=.028\right)$, indicating an unequal distribution of pulmonary blood flow. The ratio of pulmonary to systemic flow (Qp/Qs) was comparable between patients with left-sided PVO and those in the control group (0.97 vs $0.96, P=.748$ ), reflecting compensatory flow in the right lung offsetting diminished flow in the left lung of PVO patients. The cardiothoracic ratio was comparable between the left-sided PVO and control groups ( 0.54 vs $0.54, P=.111$ ) (Table 3 ). 


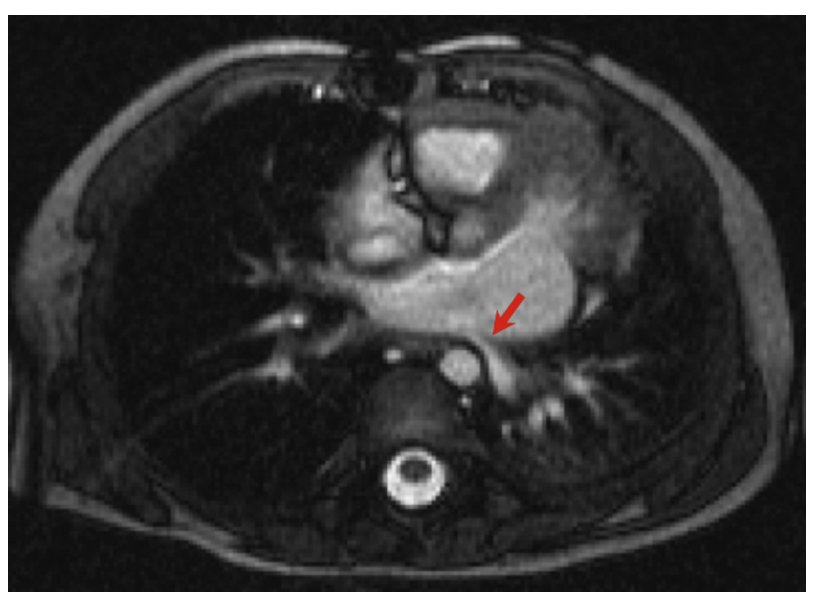

FIGURE 1. Hypothesis of anatomic factor contributing left-sided pulmonary vein obstruction. Arrow shows narrowed left pulmonary vein between the heart and descending aorta.

\section{Clinical Outcomes}

After surgical repair of PVO using the sutureless technique, the confluence of the left pulmonary veins with the left atrium was shifted laterally with elimination of PVO in 4 patients (Figure 3, $A$ and $B$ ). Three patients, however, did not have improved PV augmentation with the sutureless technique and had residual PVO, determined by echocardiography.

Two patients died after left-sided PVO was diagnosed (Table 1). Patient no. 1 had a sutureless repair and was waiting for a Fontan operation, without any evidence of recurrent PVO or pulmonary hypertension, and subsequently died of mechanical valve thrombosis and cardiac arrest. Another patient (no. 9) had a sutureless repair at the time of a bidirectional cavopulmonary shunt procedure but developed low cardiac output and desaturation, owing to increased pulmonary artery pressure, resulting in multiorgan failure and subsequent death. Two patients had significant AVVR and ventricular dysfunction and required heart transplantation. In total, 7 (46\%) patients with left-sided PVO were considered to have failure of single-ventricle physiology, or failure to achieve Fontan completion, owing to pulmonary hypertension $(\mathrm{n}=4)$, need for heart transplantation $(\mathrm{n}=2)$, or protein-losing enteropathy $(\mathrm{n}=1)$; (failure group $n=7$ ) (Table 1). Eight (54\%) of 15 patients had no evidence of pulmonary hypertension and achieved or

TABLE 1. Clinical summary for patients with left-sided PVO

\begin{tabular}{|c|c|c|c|c|c|c|c|c|c|c|c|c|}
\hline \multirow[b]{2}{*}{ No. } & \multirow[b]{2}{*}{ Diagnosis } & \multirow{2}{*}{$\begin{array}{c}\text { Timing of } \\
\text { PVO } \\
\text { diagnosis } \\
\end{array}$} & \multirow[b]{2}{*}{$\begin{array}{c}\text { Affected } \\
\text { PV }\end{array}$} & \multirow{2}{*}{$\begin{array}{c}\text { PVO } \\
\text { diagnosed } \\
\text { by echo- } \\
\text { cardiography? }\end{array}$} & \multicolumn{2}{|c|}{ Catheterization } & \multicolumn{2}{|c|}{ Echocardiography } & \multirow[b]{2}{*}{$\begin{array}{c}\text { Last } \\
\text { status }\end{array}$} & \multirow[b]{2}{*}{$\begin{array}{c}\text { Reason } \\
\text { for death }\end{array}$} & \multirow{2}{*}{$\begin{array}{c}\text { Fontan } \\
\text { completion/ } \\
\text { candidate? }\end{array}$} & \multirow{2}{*}{$\begin{array}{c}\text { Reason for } \\
\text { failure to } \\
\text { achieve Fontan } \\
\text { completion } \\
\end{array}$} \\
\hline & & & & & $\begin{array}{c}\text { PAP } \\
(\mathbf{m m ~ H g}) \\
\end{array}$ & $\begin{array}{c}\text { PVR } \\
(\text { Unit/m² }) \\
\end{array}$ & AVVR & $\begin{array}{c}\text { Ventricular } \\
\text { function }\end{array}$ & & & & \\
\hline 1 & TA, TGA & $\mathrm{s} / \mathrm{p}$ BCPS & LL & No & 15 & NA & 2 & 0 & Dead & $\begin{array}{l}\text { Mechanical } \\
\text { valve } \\
\text { thrombosis }\end{array}$ & Yes & $\begin{array}{l}\text { Mechanical valve } \\
\text { thrombosis }\end{array}$ \\
\hline 2 & TA, TGA & s/p Fontan & LL & No & 12 & NA & 1 & 0 & Alive & - & Yes & - \\
\hline 3 & DORV & s/p BCPS & LU, LL & Yes & 9 & 3.13 & 2 & 0 & Alive & - & Yes & - \\
\hline 4 & $\mathrm{TA}$ & $\mathrm{s} / \mathrm{p}$ BCPS & LU & Yes & 21 & 6.70 & 0 & 0 & Alive & - & No & $\begin{array}{l}\text { Pulmonary } \\
\text { hypertension }\end{array}$ \\
\hline 5 & DORV & s/p BCPS & LU, LL & No & 10 & NA & 2 & 0 & Alive & - & Yes & - \\
\hline 6 & DORV & s/p BCPS & LL, RL & No & 9 & NA & 1 & 1 & Alive & - & Yes & - \\
\hline 7 & HLHS & s/p Norwood & $1 \mathrm{LL}$ & No & 22 & NA & 2 & 3 & Alive & - & No & $\begin{array}{l}\text { Heart } \\
\quad \text { transplantation }\end{array}$ \\
\hline 8 & HLHS & s/p Norwood & $1 \mathrm{LU}, \mathrm{LL}$ & No & 22 & NA & 2 & 2 & Alive & - & No & $\begin{array}{l}\text { Heart } \\
\quad \text { transplantation }\end{array}$ \\
\hline 9 & DIRV & s/p Norwood & LU, LL & Yes & 23 & NA & 2 & 1 & Dead & $\begin{array}{l}\text { Multi-organ } \\
\text { failure }\end{array}$ & No & $\begin{array}{l}\text { Pulmonary } \\
\text { hypertension }\end{array}$ \\
\hline 10 & HLHS & s/p Norwood & $1 \mathrm{LU}, \mathrm{LL}$ & Yes & 24 & NA & 1 & 0 & Alive & - & No & $\begin{array}{l}\text { Pulmonary } \\
\text { hypertension }\end{array}$ \\
\hline 11 & DIRV & s/p BCPS & LU & No & 10 & 2.17 & 0 & 1 & Alive & - & Yes & - \\
\hline 12 & HLHS & $\mathrm{s} / \mathrm{p}$ BCPS & LU, LL & No & 20 & NA & 1 & 0 & Alive & - & No & $\begin{array}{r}\text { Protein-losing } \\
\text { enteropathy }\end{array}$ \\
\hline 13 & DIRV & s/p BCPS & LU, LL & Yes & 12 & NA & 2 & 0 & Alive & - & Yes & - \\
\hline 14 & TA, TGA & s/p BCPS & $\mathrm{LL}$ & Yes & 9 & 2.13 & 1 & 0 & Alive & - & Yes & - \\
\hline 15 & HLHS & s/p Norwood & $1 \mathrm{LU}, \mathrm{LL}$ & Yes & 18 & 8.10 & 1 & 0 & Alive & - & No & $\begin{array}{l}\text { Pulmonary } \\
\text { hypertension }\end{array}$ \\
\hline
\end{tabular}

For AVVR, $0=$ none, $1=$ mild, $2=$ moderate, $3=$ severe; for ventricular function, $0=$ normal, $1=$ mildly decreased; $2=$ moderately decreased; $3=$ severely decreased. $A V V R$, Atrioventricular valve regurgitation; $P V O$, pulmonary vein obstruction; $P V$, pulmonary vein; $P A P$, pulmonary artery pressure; $P V R$, pulmonary vascular resistance; $T A$, tricuspid atresia; $T G A$, transposition of the great arteries; $s / p$, post status; $B C P S$, bidirectional cavopulmonary shunt; $L L$, left lower; $N A$, not assessed; $D O R V$, double-outlet right ventricle; $L U$, left upper; $R L$, right lower; $H L H S$, hypoplastic left-heart syndrome; $D I R V$, double-inlet right ventricle. 


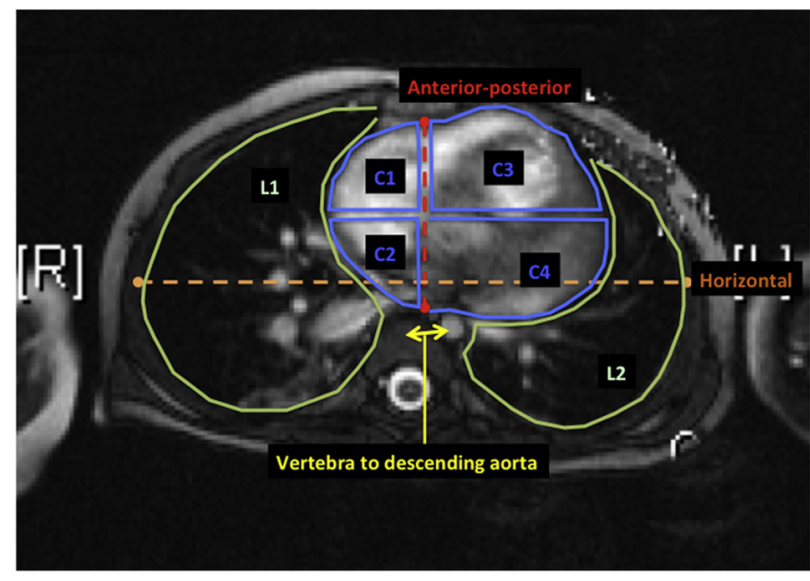

\begin{tabular}{l|l}
\hline Anterior-posterior & Posterior sternal plate - Anterior margin of vertebra \\
\hline Horizontal & Maximum horizontal dimension \\
\hline Vertebra to descending aorta & Distance between vertebra and descending aorta \\
\hline C1 & Right anterior cardiac area \\
C2 & Right posterior cardiac area \\
C3 & Left anterior cardiac area \\
C4 & Left posterior cardiac area \\
\hline Cardiac & Total cardiac area $(C 1+C 2+C 3+C 4)$ \\
L1 & Right lung area \\
L2 & Left lung area \\
Lung & Total lung area $(L 1+L 2)$ \\
\hline
\end{tabular}

FIGURE 2. Measurement of intrathoracic structures by cardiac magnetic resonance. Axial slice at the level of left lower pulmonary vein was chosen from cardiac magnetic resonance. All measurement was normalized by thoracic dimension. Antero-posterior dimension: (posterior sternal plate to anterior margin of vertebra)/(posterior sternal plate to posterior margin of the lungs). Horizontal dimension: (maximum horizontal dimension of thoracic cavity)/(posterior sternal plate to posterior margin of the lungs). Distance from vertebra to aorta: distance from anterior margin of vertebra to center of descending aorta normalized by using vertical and horizontal dimension of thoracic cavity.

were candidates for Fontan completion (success group $\mathrm{n}=8)$. In contrast, 11 of $12(92 \%)$ patients in the control group subsequently had Fontan completion or are considered satisfactory candidates awaiting a Fontan operation.

\section{Relationship Between Clinical Outcomes and Anatomic Characteristics}

Among patients with left-sided PVO, intrathoracic dimensions were compared between patients who achieved or were awaiting Fontan completion $(\mathrm{n}=8)$ and those who failed to achieve Fontan completion $(n=7)$. Normalized distance from the vertebra to the descending aorta did not differ between the groups ( 0.09 vs $0.09, P=.215)$. Indexed cardiac area and cardiac/thoracic ratio were significantly larger in the failure group (indexed cardiac area: 9.71 vs $5.88 \mathrm{~mm}^{2} /$ $\mathrm{m}^{2}, \quad P=.009$; cardiac/thoracic ratio: 0.49 vs 0.39 , $P=.001)$. The failure group had a larger heart in the left-
TABLE 2. Anatomic measurement in cardiac magnetic resonance

\begin{tabular}{|c|c|c|c|}
\hline & $\operatorname{PVO}(\mathbf{N}=15)$ & Control $(N=12)$ & $P$ value \\
\hline $\begin{array}{l}\text { Anterior- } \\
\text { posterior }\end{array}$ & $0.70(0.62-0.74)$ & $0.64(0.63-0.67)$ & .263 \\
\hline Horizontal & $1.44(1.31-1.51)$ & $1.40(1.37-1.50)$ & .660 \\
\hline $\begin{array}{l}\text { Vertebra to } \\
\text { descending } \\
\text { aorta }\end{array}$ & $0.09(0.08-0.10)$ & $0.08(0.07-0.09)$ & .049 \\
\hline Cardiac $\left(\mathrm{mm}^{2}\right)$ & $6278(5828-9037)$ & $6666(5669-7189)$ & .186 \\
\hline Lung $\left(\mathrm{mm}^{2}\right)$ & $10,020(8741-10,645)$ & $10,804(9378-12,431)$ & .127 \\
\hline Total thoracic & $16,376(15,692-20,047)$ & $17,193(15,441-19,454)$ & .865 \\
\hline $\begin{array}{l}\text { Cardiac/ } \\
\text { thoracic }\end{array}$ & $0.43(0.39-0.49)$ & $0.38(0.36-0.38)$ & .035 \\
\hline $\begin{array}{l}\text { Left cardiac } \\
\qquad\left(\mathrm{mm}^{2}\right)\end{array}$ & $5127(4163-5841)$ & $4383(3968-5014)$ & .112 \\
\hline $\begin{array}{l}\text { Left thoracic } \\
\qquad\left(\mathrm{mm}^{2}\right)\end{array}$ & 9134 (8014-10,107) & 8647 (8201-9810) & .879 \\
\hline $\begin{array}{l}\text { Left/right } \\
\text { cardiac }\end{array}$ & $2.42(1.99-2.90)$ & $2.25(1.78-3.02)$ & .730 \\
\hline $\mathrm{C} 3 /$ cardiac & $0.40(0.38-0.42)$ & $0.38(0.37-0.44)$ & .921 \\
\hline $\mathrm{C} 4 /$ cardiac & $0.30(0.26-0.34)$ & $0.30(0.25-0.32)$ & .748 \\
\hline $\mathrm{C} 3 /$ left thoracic & $0.50(0.44-0.57)$ & $0.42(0.33-0.48)$ & .047 \\
\hline $\begin{array}{l}\text { Left cardiac/ } \\
\text { left thoracic }\end{array}$ & $0.60(0.52-0.64)$ & $0.52(0.47-0.54)$ & .014 \\
\hline $\mathrm{C} 4 / \mathrm{C} 3$ & $0.71(0.63-0.84)$ & $0.67(0.60-0.90)$ & .961 \\
\hline
\end{tabular}

All measurement was normalized by thoracic dimension. Antero-posterior dimension: (posterior sternal plate to anterior margin of vertebra)/(posterior sternal plate to posterior margin of the lungs). Horizontal dimension: (maximum horizontal dimension of thoracic cavity)/(posterior sternal plate to posterior margin of the lungs), Distance from vertebra to aorta: distance from anterior margin of vertebra to center of descending aorta normalized by using vertical and horizontal dimension of thoracic cavity. Cardiac: $\mathrm{C} 1+\mathrm{C} 2+\mathrm{C} 3+\mathrm{C} 4$; Lung: L1 + L2; Total Thoracic: Cardiac + lung; Left Cardiac: C3 + C4; Left Thoracic: C3 + C4 + L2 ; Right Cardiac: $\mathrm{C} 1+\mathrm{C} 2 . P V O$, Pulmonary vein obstruction.

sided portion of the thoracic cavity ( $\mathrm{C} 3 /$ left thoracic area: 0.58 vs $0.49, P=.035$ ). Figure 4 shows the relationship between heart size, location of descending aorta, and clinical outcome. Patients with left-sided PVO had more cardiomegaly and antero-laterally displaced descending aortae compared with patients without PVO. Furthermore, cardiomegaly was associated with failed Fontan completion (Figure 4).

\section{DISCUSSION}

Pulmonary vein obstruction is associated with increased pulmonary vascular resistance and is considered an adverse prognostic factor with regard to proceeding to a Fontan procedure. $^{4,5}$ Previous studies have reported an anatomic association between left-sided PVO, the descending aorta, and the left atrium. ${ }^{1-3}$ Although left-sided PVO is often seen in patients with single-ventricle physiology in clinical practice, little study has been done of the anatomic/geometric substrate for PVO in the single-ventricle population.

\section{Anatomic and Physiologic Characteristics in Patients With Left-Sided Pulmonary Vein Obstruction}

Previous studies have reported pulmonary vein compression between the atrium and descending aorta. ${ }^{1-3}$ Kawahira 
TABLE 3. Physiologic data

\begin{tabular}{|c|c|c|c|}
\hline & $\operatorname{PVO}(\mathbf{N}=15)$ & Control $(N=12)$ & $P$ value \\
\hline \multicolumn{4}{|c|}{ Cardiac magnetic resonance } \\
\hline LPA size $\left(\mathrm{mm}^{2} / \mathrm{m}^{2}\right)$ & $40.2(32.3-40.7)$ & $53.2(50.2-53.2)$ & .153 \\
\hline LPA flow $\left(1 / \mathrm{min} / \mathrm{m}^{2}\right)$ & $0.27(0.18-0.40)$ & $0.86(0.71-1.06)$ & .003 \\
\hline LPVs flow $\left(1 / \mathrm{min} / \mathrm{m}^{2}\right)$ & $1.02(0.80-1.39)$ & $1.57(1.54-1.73)$ & .061 \\
\hline Left upper PV flow & $0.60(0.40-0.92)$ & $0.61(0.44-0.72)$ & .657 \\
\hline Left lower PV flow & $0.60(0.38-0.70)$ & $0.87(0.80-1.03)$ & .084 \\
\hline RPA size $\left(\mathrm{mm}^{2} / \mathrm{m}^{2}\right)$ & $47.9(43.8-51.4)$ & $42.3(42.3-42.8)$ & .145 \\
\hline RPA flow $\left(1 / \mathrm{min} / \mathrm{m}^{2}\right)$ & $1.76(1.02-2.17)$ & $1.21(0.75-1.24)$ & .162 \\
\hline RPVs flow $\left(1 / \mathrm{min} / \mathrm{m}^{2}\right)$ & $2.25(1.73-2.43)$ & $1.47(1.25-1.86)$ & .025 \\
\hline Right upper PV flow & $1.18(0.93-1.37)$ & $0.85(0.67-1.17)$ & .228 \\
\hline Right lower PV flow & $0.97(0.86-1.17)$ & $0.71(0.62-1.02)$ & .058 \\
\hline LPA/RPA size ratio & $0.78(0.76-0.85)$ & $1.26(1.17-1.26)$ & .106 \\
\hline LPA/RPA flow ratio & $0.17(0.10-0.19)$ & $0.59(0.58-1.32)$ & .007 \\
\hline LPVs/RPVs flow ratio & $0.52(0.47-0.72)$ & $1.05(0.86-1.36)$ & .028 \\
\hline $\operatorname{VEDVi}\left(\mathrm{ml} / \mathrm{m}^{2}\right)$ & $129(97-179)$ & $117(112-134)$ & .276 \\
\hline VESVi $\left(\mathrm{ml} / \mathrm{m}^{2}\right)$ & $56(40-98)$ & $47(42-71)$ & .152 \\
\hline Qp/Qs & $0.97(0.91-1.07)$ & $0.96(0.91-0.98)$ & .748 \\
\hline \multicolumn{4}{|l|}{ Catheterization } \\
\hline PAP (mm Hg) & $15(10-21)$ & $11(9-13)$ & .048 \\
\hline PVR (WU/m²) & $3.13(2.17-6.70)$ & $2.32(1.48-2.65)$ & .040 \\
\hline VEDP $(\mathrm{mm} \mathrm{Hg})$ & $8(6-11)$ & $7(5-9)$ & .416 \\
\hline \multicolumn{4}{|l|}{ Radiograph } \\
\hline Cardiothoracic ratio & $0.54(0.52-0.58)$ & $0.54(0.51-0.55)$ & .111 \\
\hline $\begin{array}{l}\text { vein; } V E D V i \text {, ventricular en } \\
\text { systolic volume index; } Q p / Q s \text {, }\end{array}$ & on; $L P V$, left pulm & nary vein; $P V$, puln & nary vein; \\
\hline
\end{tabular}

and colleagues ${ }^{2}$ reported that a combination of the pulmonary venous connection to the atrium with a morphologically right appendage, with the descending aorta and the heart on the same side of the chest, poses a risk of pulmonary vein compression. Otsuki and colleagues ${ }^{3}$ defined 3 types of PVO by using computed tomography, in which 1 type of PVO was the result of compression by surrounding organs. O'Donnell and colleagues ${ }^{1}$ examined 1995 patients undergoing catheterization and identified $26(1.3 \%)$ patients who had left aortic arch in association with leftsided PVO. In the present study, we used axial CMR to show that the combination of cardiomegaly and a laterally displaced descending aorta was associated with development of left-sided PVO.

\section{Cardiac Magnetic Resonance and Echocardiography as Diagnostic Tools for Left-Sided PVO}

In the current study, left-sided PVO was associated with intrapulmonary flow redistribution with a higher ratio of right/ left pulmonary vein flows. Interestingly, only half of the patients with left-sided PVO diagnosed by CMR had flow acceleration at the site of PVO documented by echocardiography. These data suggest that flow redistribution away from the site of PVO may diminish the potential for echocardiography to detect hemodynamically significant left-sided PVO if flow acceleration or gradients are considered critical to the echocardiographically defined diagnosis. These findings suggest that CMR has greater sensitivity to detect PVO. Despite the apparently greater sensitivity of CMR, echocardiography is more commonly used to screen patients for PVO. ${ }^{8}$

Another disadvantage of echocardiography includes the difficulty in determining the dimensions of the pulmonary veins within the lung parenchyma. Computed tomography and magnetic resonance imaging are helpful in determining the pulmonary vein dimensions within the lung parenchyma. ${ }^{3}$ CMR can provide both anatomic (dimensions) and physiologic (flow) information for individual pulmonary veins within the lung parenchyma. ${ }^{9,10}$ Thus, we believe that CMR is a useful diagnostic tool to assess pulmonary vein anatomy and physiology and may have greater sensitivity than echocardiography in making the diagnosis of left-sided PVO, with the additional advantage of providing better visualization of the dimensions of the pulmonary veins "upstream" from the site of obstruction. In light of the sensitivity of CMR to detect lesions outside the boundaries of echocardiography, it may be important to utilize CMR in more liberal fashion. We speculate that compression of the pulmonary veins by the heart may be an early event in the pathogenesis of increased pulmonary vascular resistance, subsequent single-ventricle dysfunction, and progression to Fontan failure in a subset of patients with anatomic predisposition to PVO.

\section{Surgical Treatment for Left-Sided PVO}

In this study, about half of patients with left-sided PVO underwent surgical treatment. All operations utilized the "sutureless technique" that has been used in our institution for total anomalous pulmonary vein connection or recurrent PVO. ${ }^{7,11,12}$ The unproven rationale for the use of the sutureless technique is to avoid the direct anastomosis between the pulmonary veins and the left atrium, and thereby minimize postoperative inflammation and subsequent fibrosis formation, resulting in less recurrent obstruction. Despite this strategy, recurrent PVO was seen in 3 of 7 patients without improvement in the anatomic dimension of the pulmonary vein orifice. As we gain more insight into the role of the anatomic relationships between the heart mass and the descending aorta, our surgical strategy is shifting to the concomitant objectives of repairing the site of anatomic narrowing and shifting the site of the pulmonary vein-left atrial junction laterally beyond the descending aorta (Figure 3).

\section{Clinical Relevance of Left-Sided PVO in Single-Ventricle Physiology}

Our study suggests that patients with single-ventricle physiology and cardiomegaly are vulnerable for development of left-sided PVO. We speculate that ventricular volume overload, especially after stage I palliation with systemic-to-pulmonary shunt, with associated AVVR and 

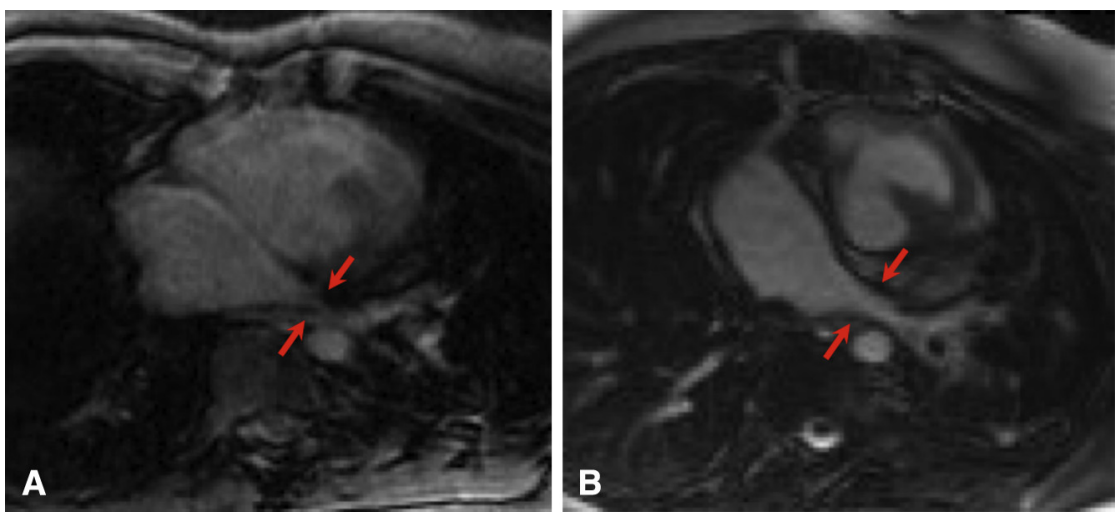

FIGURE 3. Left lower pulmonary vein before and after sutureless repair. A, Before sutureless repair, the left lower PV is narrowed by compression of the heart and descending aorta. B, After sutureless repair, the confluence of the left lower PV to the atrium is well augmented.

ventricular dysfunction contributes to anatomic relationships that promote potential for PVO, and this potential might be further increased in patients with an anterolaterally displaced thoracic aorta. Although comparison of the end-diastolic and end-systolic volumes between groups did not demonstrate a significant difference, the relative size of the cardiac mass within the context of the size of the thoracic cavity (cardiac/thoracic ratio, Table 2) was greater in the PVO group, suggesting that relative cardiomegaly may contribute to the development of PVO.

We did not, however, demonstrate a strong relationship between AVVR and left-sided PVO. The lack of a detectable relationship between AVVR and PVO may be related to the small number of patients in this study. If a relationship among AVVR, relative cardiomegaly, and PVO can be identified in a larger study, then conceivably, indications to intervene earlier on single-ventricle patients with AVVR and anterolaterally displaced aorta to decrease ventricular size and thereby decrease the propensity to developing left-sided PVO might be contemplated. Furthermore, there may be a patient subset in whom a left thoracotomy can be used to move the descending aorta posteriorly to reduce compression on the left-sided pulmonary veins. We have not yet utilized this approach, but recognize that this technique has been described for tracheal stenosis. ${ }^{13}$ If utilized, we speculate that performing a descending aortopexy early in the PVO process will be important as a means to preempt development of stenotic fibrosis within the lumen of the pulmonary vein.

\section{Limitations}

The retrospective nature of this study poses significant limitations in the interpretation of results. Because we

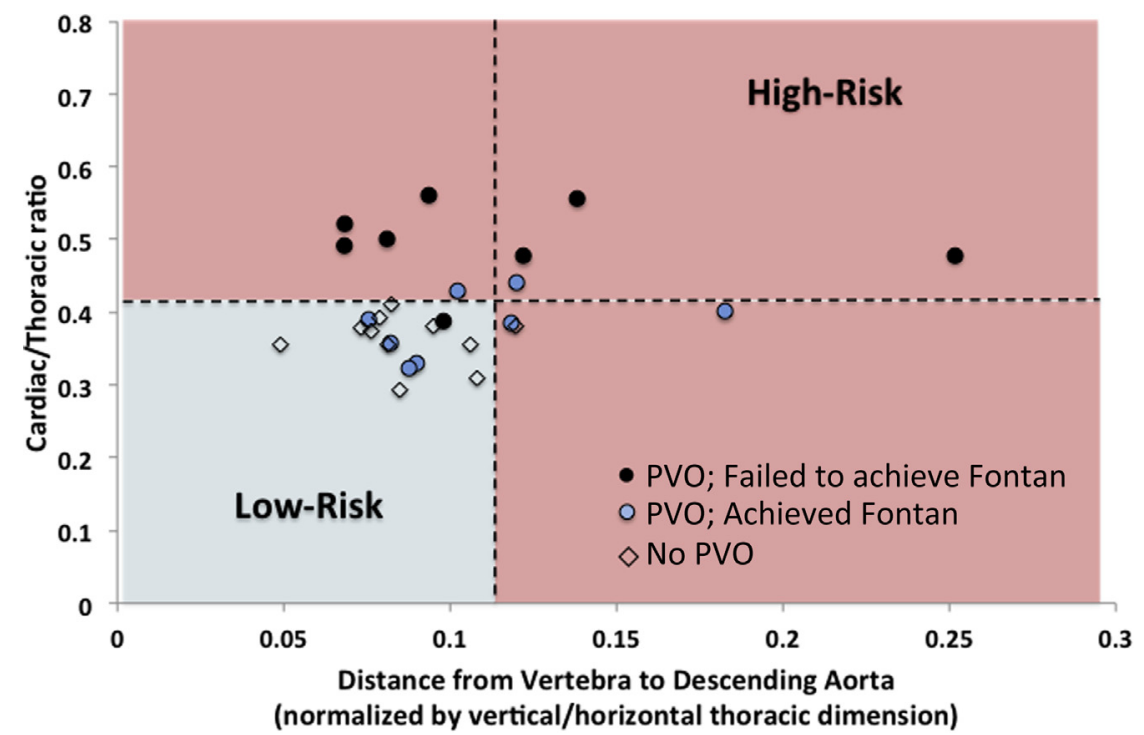

FIGURE 4. Relationship between clinical outcomes and anatomic characteristics. Patients with left-sided PVO (circle) had more cardiomegaly and anterolaterally located descending aorta compared with patient without PVO (diamond). Cardiomegaly was associated with failed Fontan completion (closed diamond). $P V O$, Pulmonary vein obstruction. 
were constrained to limit our analysis to patients who had CMR performed as part of the diagnostic work-up, the study cohort may not be representative of the more general population of single-ventricle patients with PVO. In our more recent practice, however, we nearly always obtain a CMR for patients with suspected PVO. A second limitation is that the control group is relatively small in comparison to the study group. The small size of the control group may have contributed to a failure to detect anatomic dimensions in the control patients without PVO that were similar to those in the PVO patients.

\section{CONCLUSIONS}

The combination of relative cardiomegaly within the context of the thoracic cavity at the level of the pulmonary veins and antero-lateral displacement of the aorta is associated with left-sided PVO and subsequent failure to achieve Fontan completion. Further characterization of this unique geometric association may help inform decision making in the timing of interventions (eg, treatment of AVVR and related cardiomegaly) and guide the intraoperative objectives at the time of PVO repair.

\section{Conflict of Interest Statement}

Authors have nothing to disclose with regard to commercial support.

\section{References}

1. O'Donnell CP, Lock JE, Powell AJ, Perry SB. Compression of pulmonary veins between the left atrium and the descending aorta. Am J Cardiol. 2003;91:248-51.

2. Kawahira Y, Kadoba K, Matsuda H. Compression of the pulmonary veins by the descending aorta in patients corrected surgically by the Fontan procedure. Cardiol Young. 1998;8:86-9.

3. Ohtsuki S, Baba K, Kataoka K, Ohno N, Okamoto Y, Ishino K, et al. Usefulness of helical computed tomography in diagnosing pulmonary vein stenosis in infants. Acta Med Okayama. 2005;59:93-8.

4. Kouchoukos N. Cardiac surgery. Oxford, England: Churchill Livingstone; 2003.

5. Anderson R. Pediatric cardiology. Oxford, England: Churchill Livingstone; 2009.

6. Grosse-Wortmann L, Al-Otay A, Yoo SJ. Aortopulmonary collaterals after bidirectional cavopulmonary connection or Fontan completion: Quantification with MRI. Circ Cardiovasc Imaging. 2009;2:219-25.

7. Najm HK, Caldarone CA, Smallhorn J, Coles JG. A sutureless technique for the relief of pulmonary vein stenosis with the use of in situ pericardium. J Thorac Cardiovasc Surg. 1998;115:468-70.

8. Smallhorn JF, Freedom RM, Olley PM. Pulsed Doppler echocardiographic assessment of extraparenchymal pulmonary vein flow. J Am Coll Cardiol. 1987;9:573-9.

9. Grosse-Wortmann L, Al-Otay A, Goo HW, Macgowan CK, Coles JG, Benson LN, et al. Anatomical and functional evaluation of pulmonary veins in children by magnetic resonance imaging. J Am Coll Cardiol. 2007;49: 993-1002.

10. Valsangiacomo ER, Barrea C, Macgowan CK, Smallhorn JF, Coles JG, Yoo SJ. Phase-contrast MR assessment of pulmonary venous blood flow in children with surgically repaired pulmonary veins. Pediatr Radiol. 2003;33:607-13.

11. Yanagawa B, Alghamdi AA, Dragulescu A, Viola N, Al-Radi OO, Mertens LL, et al. Primary sutureless repair for "simple" total anomalous pulmonary venous connection: midterm results in a single institution. J Thorac Cardiovasc Surg. 2011;141:1346-54.

12. Hickey EJ, Caldarone CA. Surgical management of post-repair pulmonary vein stenosis. Semin Thorac Cardiovasc Surg Pediatr Card Surg Annu. 2011;14: $101-8$.

13. Weber TR, Keller MS, Fiore A. Aortic suspension (aortopexy) for severe tracheomalacia in infants and children. Am J Surg. 2002;184:573-7.

Readers who found these articles interesting may also like to read the following papers found in recent and future issues of our sister publications, Seminars in Thoracic and Cardiovascular Surgery and Operative Techniques in Thoracic and Cardiovascular Surgery!

Current Readings: Jeffrey Jacobs. Long Term Management of Patients Undergoing Successful Pediatric Cardiac Surgery. Semin Thorac Cardiovasc Surg. Summer 2014;26(2):132-144.

Current Readings: Brian Kogon. Pulmonary Valve Replacement for Pulmonary Valve Insufficiency in Formerly Repaired Tetralogy of Fallot Patients. Semin Thorac Cardiovasc Surg. Expected publication August 2015.

Original Submission: Meena Nathan. Technical Performance Score as a predictor for post discharge reintervention in valve sparing Tetralogy of Fallot repair. Semin Thorac Cardiovasc Surg. Expected publication April 2015.

Editorial Commentary: Jonathan Chen. Technical performance anxiety: utility of the Technical Performance Scale in predicting later intervention after repair of Tetralogy of Fallot. Semin Thorac Cardiovasc Surg. Expected publication April 2015.

Shi-Joon Yoo. MRI as a decision making tool in congenital heart disease surgery. Oper Tech Thorac Cardiovasc Surg. Summer 2014;19(2):152-163.

Pascal Vouhe. Valve Sparing Konno and HOCM in Children. Oper Tech Thorac Cardiovasc Surg. Summer 2014;19(2):164-178.

Jose Pedro da Silva. Pulmonary root translocation for anatomical repair of congenitally corrected transposition of the Great Arteries. Oper Tech Thorac Cardiovasc Surg. Expected publication February 2015. 